\title{
A Model for Physical Activity Behavioural Change in Middle Aged and Older People with Type 2 Diabetes
}

\author{
Mingyue Zheng ${ }^{1}$, Shenqiao Yang ${ }^{1 *}$, Yanting $\mathrm{Liu}^{2}$, Qian $\mathrm{He}^{3}$, and Peng $\mathrm{Hu}^{1}$ \\ ${ }^{1}$ School of Health Rehabilitation, Chengdu University of Traditional Medicine, 611137, China \\ ${ }^{2}$ School of Medicine and Life Sciences, Chengdu University of Traditional Medicine, 611137, China \\ ${ }^{3}$ School of Nursing, Chengdu University of Traditional Medicine, 611137, China
}

\begin{abstract}
Objective: To identify key determinants of increased PA level among adults with T2DM to improve a hierarchical model, based on social cognitive theory (SCT) and Ecological Models. It hypothesises and clarifies how these determinants relate to physical activity which is important to evidencebased PA interventions in middle aged and older people with T2DM. Methods: Full transcript studies in English were searched in the following databases: CINAHL, Medline on OvidSP, PubMed, and PsycINFO. Included articles were selected by following these combined terms: type 2 diabetes, physical activity, exercise, physical inactivity, correlates, barriers, theory, self-efficacy, ecological models. And they $(n=124)$ met the following criteria: 1) T2BD, aged 35 and over; 2) reporting determinants or factors 3) indicated physical activity or exercise as an outcome variable. Additional records identified via bibliographies $(\mathrm{n}=4)$, duplicates were removed $(n=95)$, non-full-text articles $(n=8)$ and no-English $(n=2)$ were excluded. Finally, of the 21 articles retrieved from databases (9 of them are reviewed studies), only 12 original articles including qualitative and quantitative study were reviewed. Results: The determinants are divided into four classifications; physical, psychological, social and environmental factors, adapted combined SCT with Ecological Model of physical activity with T2MD in middle aged older adults. Self-efficacy is the core mediators with physical, environmental, and social factors, that fact is the core of SCT. Self-efficacy had an indirective negative influence by physical factors particular regions with physical barriers such as cold weather, low-density land use. Therefore, managing self-efficacy is proposed to effectively change for physical activity. It is hypothesised that improve social supports from family may help people with T2DM increase the physical activity level. Conclusion: Therefore, it is evident from the above that many factors of PA in middle aged and older people with T2DM exist. And self-efficacy is an important determinant with PA. There is a need to clarify whether these variables are determinants and the causality between these variables. Nonetheless, theory-basement approach to studying PA in this population is required based upon this study
\end{abstract}

\section{Introduction}

World Health Organization (2016) reports that diabetes will become the seventh leading cause of death by 2030 . One adult in ten will live with diabetes, which means that around 642 million adults will have this disease by 2040 worldwide (International Diabetes Federation diabetes atlas, 2015). The prevalence of diabetes is predicted to rise to four million in the UK by 2025 (Diabetes UK, 2015). Moreover, the treatment of diabetes and its complications is estimated will cost $£ 14$ billion pounds per year. Additionally, $90 \%$ of diabetics have Type 2 diabetes (T2DM) and the majority of them are adults in the UK. There are some risk factors of T2DM such as overweight, smoking. One of the risk factors of T2DM is age; there is an increasing tendency of risk for T2DM on age. Specifically, people who are over 40 years old (or over 25 for those are Black African, South Asian or African-Caribbean) have a significantly higher risk of T2DM (https://www.diabetes.org.uk, 2009). Physical activity (PA) plays a crucial part in the prevention of T2DM; and it is a cost-effective method (Diabetes UK, 2015). Thomas, Elliott, and Naughton (2006) reviewed 14 randomised controlled trials (included 377 participants) comparing no PA against PA in T2DM, it stated that the PA intervention obviously enhanced glycaemic control (-0.6\% HbA1c, 95\% confidence interval $(\mathrm{CI})-0.9$ to $-0.3, \mathrm{P}<.05)$. Unfortunately, the majority of adult patients with T2DM were failed to meet the minimum recommendations (150 minutes per week) for PA (ADA, 2017). According to Thomas, (2004), the levels of PA are low among the diabetes population in the UK, with only $34 \%$ of diabetic patients meet this recommended PA guideline due to the

\footnotetext{
* Corresponding author: 346307377@qq.com
} 
difficulties in social factors such as lack of local facilities $(p=.03)$ or leisure-time $(p=.012)$.

There are many studies that have explored some possible reasons for physical inactivity in the general population such as lake of time and social supports ((Baranowski, Anderson, and Carmack, 1999, Orleans, 2008, and Trost et al., 2002). However, particular diseases need particular PA guidelines and interventions, middle aged and older adults also need the intervention guidelines for themselves because they are physically inactive and high risk of T2DM basing on above evidence. However, only a few studies have focused on this population so far. For example, a cross-sectional study $(n=1928)$ has highlighted that patients with T2DM had lower PA efficacy and readiness than healthy adults in Canada (Grace et al., 2006). A review comments that the main reasons for inactivity in diabetic adults (aged 35 and over) were physiological predicted barriers $(\mathrm{p}<.01)$, without family support $(\mathrm{p}<.01)$, and lack of facilities $(p=.03)$ (Thomas, 2004). Besides, outcome expectations, goals-setting had emerged as correlations of PA in meddle aged and older people with T2DM (over 35 years old) (Boudreau\&Godin, 2009, Grace et al., 2006, Heiss\&Petosa, 2015, Lawton, 2005, and Plotnikoff et al., 2008).

Another medical sociology research suggested that there was a need to understand prevention and treatment of disease, not only regarding individuals' levels but also within the broader social context of their lives (Lawton et al., 2003). For example, one cross-sectional study $(\mathrm{n}=1580)$ by Ferrand, Perrin, and Nasarre, (2008) showed that accessibilities, social support, weather, have also been associated with PA based on ecological impacts. Thus, it is required to recognise the physical, physiological, environmental and social determinants and factors in increasing the PA level, particularly in middle-aged and older people (aged over 35) with T2DM. Therefore, this article aims to identify key determinants of increased PA level among adults with T2DM to improve a hierarchical model, based on social cognitive theory (SCT) (primary) and Ecological Models. It will hypothesise and clarify how these determinants relate to PA, which is important to evidence-based PA interventions in middle aged and older people with T2DM

\section{Methods}

Full transcript studies in English were searched in the following databases: CINAHL (Cumulative Index to Nursing \& Allied Health), Medline on OvidSP, PubMed, and PsycINFO. This review has chosen articles from 2003 up to now to update a recent review (from1985 to 2002) (Allen, 2004). Included articles were selected by following these combined terms: type 2 diabetes, physical activity, exercise, physical inactivity, correlates, barriers, theory, self-efficacy, ecological models. And they $(n=124)$ met the following criteria: 1) T2BD, aged 35 and over; 2) reporting determinants or factors 3) indicated PA or exercise as an outcome variable. Additional records identified via bibliographies $(n=4)$, duplicates were removed $(\mathrm{n}=95)$, non-full-text articles $(n=8)$ and no-English $(n=2)$ were excluded. Finally, of the 21 articles retrieved from databases ( 9 of them are reviewed studies), only 12 original articles (both qualitative and quantitative study) were reviewed in this systemic review. Including six cross-section studies adopting Social cognitive theory (SCT) or Ecological Models are summarised in Table 1.

\section{Results and discussion}

The determinants and evidence illustrated in the following section, which are divided into four classifications; physical, psychological, social and environmental factors, adapted combined SCT (primary) (Bandura, 1986) with Ecological Model (Sallis et al, 2006) of PA with T2MD in middle aged older adults. Many scientific studies regarding the factors which impact this population are based on cross-sectional studies (See Table 1). Hence, only associations between variables could be identified, but causality cannot be inferred. However, these correlates are valuable for guiding further studies.

\subsection{Physical factors}

Physical factors refer to characteristics of the individual that might impact PA such as gender, education and employment status. And individual health status may have influence on individuals' level of PA. (1) Gender: An interview $(n=23)$ presented that female participants more stressed the important of emotional support than male participants (Ferrand et al., 2008). In contrast, Trost et al. (2002) reviewed 38 studies and concluded that males are more willing to participate in PA than females. (2) Education and employment status: Lawton et al. (2005) reported participants with more years in education to be physically more active than participants with lower educational level (high school), indicating the role of education as a facilitator of PA. A crosssectional study $(n=990)$ illustrated that fulltime work participants $(\mathrm{p}<.001)$ were less frequently active than those in part-time work (Grace et al., 2006). (3) Health status: It is defined as the physical functioning of an individual (Grace et al., 2006), compare T2DM patients with non-diabetes participants, diabetic participants had a smaller range and frequency of PA $(\mathrm{p}<.001)$. Moreover, participants who are non-smokers were more regularly active than those who were smokers $(p=.001)$. Due to the fact that this cross-sectional study has a small sample size $(n=133)$ and lower self-report rate $(43.3 \%)$, this result may suggest an association between health status and PA. Additionally, an interview study $(n=31)$ reported that participants who have health problems $(67.3 \%)$ had more difficulties on PA than the healthy (33.7\%) (Lawton et al., 2005). 


\subsection{Psychological determinants}

(1)Self-efficacy: SCT suggested that self-efficacy and goals setting are the main determinants of PA (see figure 1). Heiss and Petosa (2015) found self-efficacy to be main determinant in their review; sharing an association with physical, environmental, and social factors (See Table 1). A longitudinal study base on a large randomised community sample $(n=1662)$ found the diabetic group stated expressively lower marks for selfefficacy $(p<.005)$ (Plotnikoff, Brez, and Brunet, 2003). Participants who had T2DM with a lower PA efficacy and willingness $(p<.009)$ compared with others who had cardiovascular disease. And the efficacy had a negative association with physical and ecological obstacles such as low-density land usage and cold weather (Grace et al., 2006). Moreover, a longitudinal study included 2311
T2DM (age over 50) (Plotnikoff et al., 2006). It explored the associations between self-efficacy and other factors (barriers, social supports, goals setting). It concluded that the association of self-efficacy and barriers $(\beta=-.28$, $\mathrm{p}<.01)$ and social support $(\beta=.21, \mathrm{p}<.01)$ were weak. However, a direct pathway of self-efficacy on goals was significant $(\beta=.62, \mathrm{p}<.005)$. Moreover, the same was true for the influence on PA $(\beta=.19, \mathrm{p}<.01)$. The recent review also (Allen, 2004) stressed that to increase selfefficacy on PA is an efficient method for exercise intervention. And One study used an accelerometer and a pedometer to measure the strength of PA; it found that self-efficacy for moderate to vigorous PA was higher cardiovascular disease participants than in T2DM participants ( $\mathrm{p}=.01)$ (Grace et al., 2006).

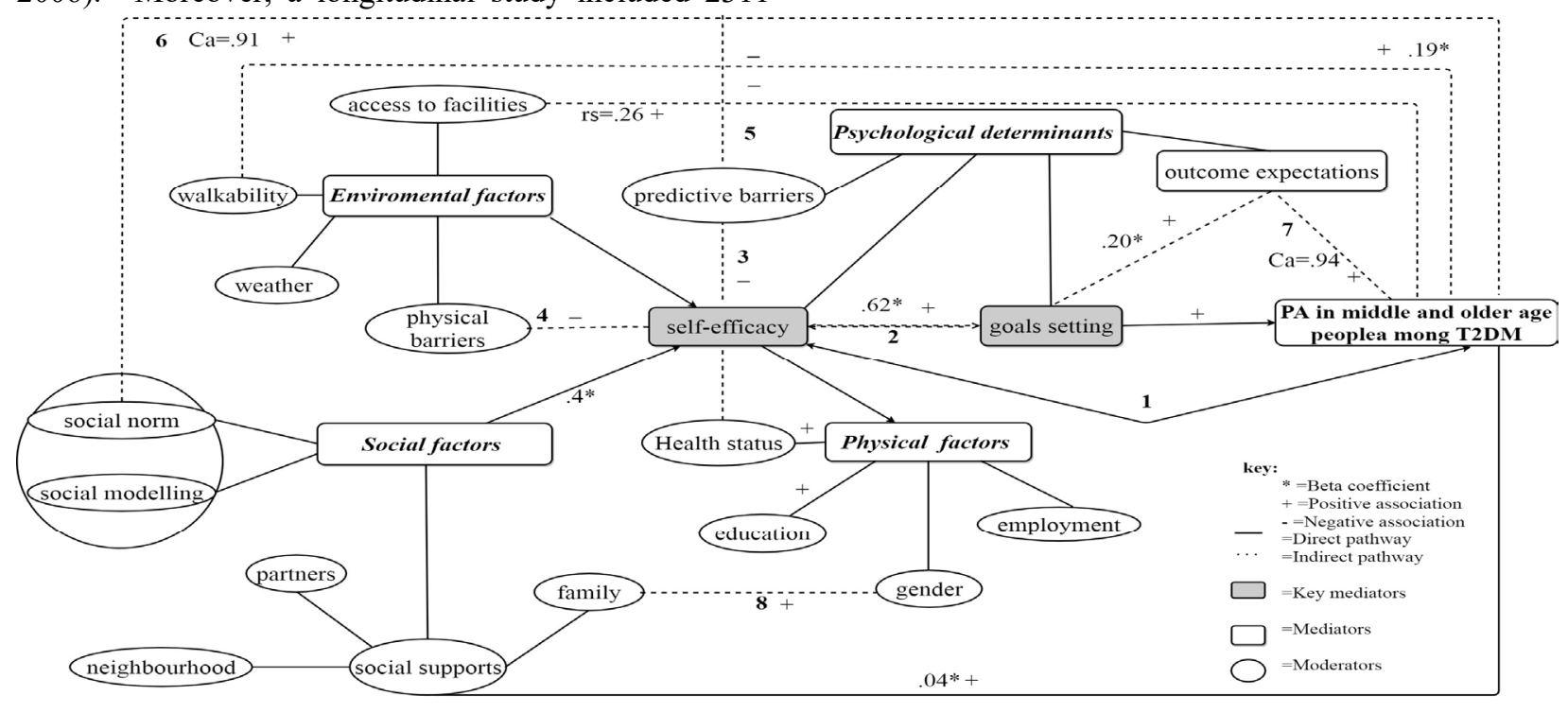

Fig.1. A hierarchical model of determinants of physical activity in middle aged and older people with T2DM * = standardised regression coefficients (beta coefficients) for determinants of influence on PA level, based on a longitudinal study $(\mathrm{n}=2311)$ (Plotnikoff et al., 2006). $\mathrm{Ca}=$ Cronbach's (Deshpande et al., 2005), $\quad$ rs= Spearman's correlation coefficient (Heiss \&Petosa, 2015)

(2) Golds setting and Outcome expectation: Outcome expectancies reflect one's belief that performing certain behaviour will cause a certain result (Bandura, 1985). Stronger goals at baseline were associated with higher levels of PA at six months. Moreover, outcome expectations were meaningfully related to goals $(\beta=.20$, $\mathrm{P}<.01$ ) but not with PA Plotnikoff et al (2008). Moreover, lower obstacles were significantly related to higher goal -setting in participants with T2DM ( $\mathrm{p}=.03)$ (Grace et al., 2006).

\subsection{Social factors}

Social factors refer to perceived individualities of the environment, such as social support, social modelling, social norm, with examples identified in figure 1. (1) Social supports: Almost all participants (23/24) in an interview study reported that they were well-supported by others had positive impacts on PA (Ferrand et al., 2008). Partnered or married participants $(64.2 \%)$ were more frequently active than those who were not $(\mathrm{p}=.03)$ (Grace et al., 2006). It might be that those participants could get support from their partners. The association between goal setting and social support was small but important in the T2DM group $(\beta=.04, \mathrm{p}<.01)$ Plotnikoff et al (2008). (2) Social modelling and social norm: Modelling was measured by participants reporting the frequency of others (partner, family, and friends) who took part in PA. This result (Cronbach's a $=.79$ ) exposed that internal consistency is acceptable (De Greef et al., 2010). Social norm is a constraining force in our social life and values. Social norm was assessed by Boudreau and Godin (2009) and De Greef et al., (2010) respectively asking whether their feelings of personal obligation were active or whether they believed that important others wanted them to be active. It seems that social norm has positive association with PA (as shown table 1). However, Deshpande et al., (2005) claimed that social cohesion and social support were not related to PA after adjustment while this cross-sectional telephone survey only included 278 individuals with T2BD and using self-report PA (See table 1). Many studies highlighted the importance of social support from family and neighbourhood for PA (Ståhl et al., 2001 and 
Brennan et al., 2003). Therefore, further studies are needed to evaluate those social factors.

\subsection{Environmental factors}

Environmental factors should be the key variables of exercise in adults among T2MD (De Greef et al., 2010 and Deshpande et al., 2005). Weather, access to facilities, and walkability were the most consistent physical associates in this review. (1) Access to facilities: Lack of facilities and opportunities to partake in PA is a moderate potential barrier that is described by an interview study (Lawton et al., 2005). The accessible researches investigated physically inactive associates with participants who did not obtain exercise equipment in the live surroundings (Boudreau and Godin, 2009, Deshpande et al. 2005, De Greef et al., 2010, and Taylor et al. 2008). After adjustment, regular PA was positively associated with use of three or more facilities (Prevalence odds ratios, 14.3 95\% CI, 3.0-67.3)
(Deshpande et al., 2005). The same results were also shown from a previous review, a main reason for inactivity included lack of local facilities for exercise in participants (age over 35) with T2DM (Thomas, 2004). (2) Walkability: Walkability had a positive association with moderate to vigorous PA $(\beta=.33, \mathrm{p}<.001)$ in a cross-sectional study (De Greef et al., 2010) (shown table 1). Similarly, the walkability also shows a positive association with PA when comparing this finding to a comprehensive review in the general population of adults in 11 countries (Sallis et al., 2009). (3) Weather and Location: According to a qualitative study $(n=31)$, 90.3\% participants described poor climatic conditions as a major barrier to PA (Lawton et al., 2005). Location might influence frequency of PA, participants who lived in rural areas and the north of Canada were less frequently doing sports in Canada (Grace et al., 2006). In a larger longitudinal study (717 adults with T2DM), there was a positive relationship between participants

Table 1 Summary of six cross-sectional studies used to assess physical, psychological, social and environmental factors in middle

\begin{tabular}{|c|c|c|c|}
\hline $\begin{array}{l}\text { Author } \\
\text { (year) }\end{array}$ & Study Population & Variables of Interest & Results (95\% CI) \\
\hline $\begin{array}{l}\text { Deshpande } \\
\text { et al., } \\
(\mathbf{2 0 0 5 )}\end{array}$ & $\begin{array}{l}278(90 \% \mathrm{~T} 2 \mathrm{DM}) \\
73.7 \% \text { female } \\
\text { Age } \geq 40 \\
\text { In the US }\end{array}$ & $\begin{array}{l}\text { IV's: access to facilities, health } \\
\text { status, social cohesion (safe from } \\
\text { traffic) and social supports } \\
\text { DV: PA (Self-report) } \\
\text { Response race: } 51.7 \%\end{array}$ & $\begin{array}{l}\text { Adjusted PORs on regular vs irregular vs no active groups } \\
\text {-access to facilities on regular PA group } 14.3(3.0-67.3) \\
\text {-social cohesion: Safe from traffic } 1.45(0.80-2.63) \\
\text {-social supports } 1.23(.65-2.34)\end{array}$ \\
\hline $\begin{array}{l}\text { Grace et al., } \\
(2006)\end{array}$ & $\begin{array}{l}1928(18 \% \\
\text { T2DM) } \\
58.6 \% \text { female } \\
\text { Age } \geq 55 \text { years } \\
\text { In Canada }\end{array}$ & $\begin{array}{l}\text { IV's: employment, health status } \\
\text { (smoke\& cardiovascular disease), } \\
\text { self-efficacy } \\
\text { DV: MVPA (Self-report) }\end{array}$ & $\begin{array}{l}\text {-fulltime work }(52.1 \% ; \chi 2=16.77, \mathrm{p}<.001) \text { temporary }(66.9 \%) \\
\text {-non-smokers }(63.8 \%) \text { vs smokers }\left(47.1 \% ; \chi^{2}=10.65, \mathrm{p}=.001\right) \\
\text {-self-efficacy for MVPA was lower in T2DM than cardiovascular disease } \\
(\mathrm{p}<\quad .001)\end{array}$ \\
\hline $\begin{array}{l}\text { Plotnikoff et } \\
\text { al., } \\
(\mathbf{2 0 0 8 )}\end{array}$ & $\begin{array}{l}2311(1614 \\
\text { T2DM) } \\
54 \% \text { female } \\
\text { Age }>40 \\
\text { In Canada }\end{array}$ & $\begin{array}{l}\text { IV's Self-efficacy, outcome } \\
\text { expectancies, social support, goals } \\
\text { setting } \\
\text { DV: PA (Self-report Leisure-time } \\
\text { PA) } \\
\text { Response race: } 43.3 \%\end{array}$ & $\begin{array}{l}\text { Only report the impacts on T2DM (compared with T1DM) } \\
\text {-association between self-efficacy and goals }(\beta=.62, \mathrm{p}<.001) \\
\text {-association between goals and outcome expectations }(\beta=.20, \mathrm{p}<.01) \\
\text {-association between social supports \& leisure-time } \mathrm{PA}(\beta=.40, \mathrm{p}<.01)\end{array}$ \\
\hline $\begin{array}{l}\text { Boudreau } \\
\text { \&Godin, } \\
(2009)\end{array}$ & $\begin{array}{l}501 \text { T2DM } \\
\text { Age }>35 \\
48 \% \text { female } \\
\text { French Canadians }\end{array}$ & $\begin{array}{l}\text { IV's: Lacking of access to facilities, } \\
\text { predictive outcomes, social norm } \\
\text { DV: PA (self-report) } \\
\text { Response race: } 33 \%\end{array}$ & $\begin{array}{l}\text { The variance of intention to engage in PA } \\
\text {-lacking of access to facilities }(\beta=.24, \mathrm{p}<.005) \\
\text { - predictive outcomes }(\beta=.38, \mathrm{p}<.0001) \\
\text {-social norm }(\beta=.29, \mathrm{p}<.0001)\end{array}$ \\
\hline $\begin{array}{l}\text { De Greef et } \\
\text { al., } \\
(2010)\end{array}$ & $\begin{array}{l}133 \text { T2DM } \\
\text { Age }>35 \\
31.6 \% \text { female } \\
\text { Dutch in Belgium }\end{array}$ & $\begin{array}{l}\text { IV's: self-efficacy; outcome } \\
\text { expectation; } \\
\text { Social modelling, social norm, } \\
\text { walkability } \\
\text { DV: PA (Self-report IPAQ\& } \\
\text { accelerometer \&pedometer) }\end{array}$ & $\begin{array}{l}\text {-association between predictive outcome and barriers }(\mathrm{Ca}=.94, \mathrm{p}<.05) \\
\text {-association between social modelling \& PA }(\mathrm{Ca}=.79, \mathrm{p}<.05) ; \text { norm\& PA } \\
(\mathrm{Ca}=.91, \mathrm{p}<.05) \\
\text {-walkability with accelerometer-based } \operatorname{MVPA}(\beta=.33, \mathrm{p}<.001)\end{array}$ \\
\hline $\begin{array}{l}\text { Heiss } \\
\text { \&Petosa } \\
(\mathbf{2 0 1 5 )}\end{array}$ & $\begin{array}{l}250 \mathrm{~T} 2 \mathrm{DM} \\
72.4 \% \text { female } \\
\text { Age } \geq 40 \text { years } \\
\text { In USA }\end{array}$ & $\begin{array}{l}\text { IV's: self-efficacy\& task self- } \\
\text { efficacy, goals setting, social } \\
\text { support, access to facilities } \\
\text { DV: MIE (self-report) } \\
\text { Response race: } 33.1 \%\end{array}$ & $\begin{array}{l}\text {-self-efficacy for making time for exercise }(\mathrm{rs}=.225, \mathrm{p}=.004) \\
\& \text { task self-efficacy }(\mathrm{rs}=.266, \mathrm{p}=.001) \\
\text {-goal setting for MIE }(\mathrm{rs}=.447, \mathrm{p}<.001) \\
\text {-social support for MIE }(\mathrm{rs}=.415, \mathrm{p}<.001) \\
\text {-access to facilities for MIE }(\mathrm{rs}=.260, \mathrm{p}=.002)\end{array}$ \\
\hline
\end{tabular}

Abbreviations: $\mathrm{CI}=$ Confidence interval; T2DM= Type 2 Diabetes; PA=Physical activity; IV's= Independent variables; DV= Dependent variable; PORs= Prevalence odds ratios; vs=Versus; MVPA=Moderate to vigorous physical activity; T1DM= Type 1 Diabetes; IPAQ= International physical activity questionnaire; Cronbach's a $=\mathrm{Ca} ; \beta=$ standardized regression coefficients; $\mathrm{MVPA}=$ moderate-intensity exercise.

Notes: $\mathrm{P}<.05$ means significant difference; $\mathrm{Ca}=$ Cronbach's $>.7$ means significant impact; $r \mathrm{~s}=$ Spearman's correlation coefficient, the strength of the correlation: $\quad .20-.39$ weak, $.40-.59$ moderate.

living nearby stores and walk to transports (Odds Ratio= 1.92, 99\% CI=1.11-3.32) (Taylor et al., 2008). Due to the precious CI and sample size, living location may increase the time of slight $\mathrm{PA}$ in this situation. A prospective cohort study $(\mathrm{n}=23,865)$ also presented that participants living in the greenest areas compared with less green places had a lower risk of diabetes (19\%) (Dalton et al., 2016). 


\subsection{A hierarchical model of determinants of PA in middle aged and older people with T2DM}

SCT is a valuable framework for evaluating correlates of PA (Bandura, 1986). However, SCT focuses on interventions that target individuals or small groups (Sallis et al., 2006). In contrast, Ecological Models refer to the public's interactions with their sociocultural and physical environments (Stokols, 1992). Based evidence above, this hierarchical model combined SCT (primary) and ecological model. It reduced social supports, norm, modelling to social factors and put access to facilities, walkability, weather, physical barriers into environmental factors (the main concept of Ecological Models). It hypothesises that the key mediators of PA in middle aged older people (age over 35) with T2DM and demonstrate their correlates with other moderators and factors.As shown in Figure 1, a positively di-direct influence the PA (1), moreover, it also indirect mediates via goals setting positively PA (2), which is a positively di-indirection pathway between self-efficacy and goals setting, because of their high correlations in PA growth (Plotnikoff et al., 2008). It is absolute that self-efficacy is the core mediators with physical, environmental, and social factors, due to it are the core of SCT. Self-efficacy had an indirective negative influence (4) by physical factors particular regions with physical barriers such as cold weather, low-density land use (Grace et al., 2006). Therefore, it proposes that manage self-efficacy is effective for change this behaviour. Predictive barriers were presented to negatively influence on self-efficacy through this mediating pathway (3) to cause lower selfefficacy of PA (De Greef et al., 2010). Predictive barriers reduced the positive influence via an indirect pathway (5) also reduced the walkability and access to facilities on PA based on evidence by Heiss \&Petosa, (2015) and Plotnikoff et al., (2006). It is hypothesised that to intervene predictive barriers on PA may lead to change in behaviour.

It is hypothesised that outcome expectations can increase PA's level via an indirect pathway (7). According to De Greef et al., (2010) and it can also moderates goals setting for positive and weak influence on P. It is hypothesised that building social modelling and norm (6) for engaging middle age people (aged $\geq 35$ ) for increasing in PA is available. Nevertheless, this pathway might be mediated by predictive barriers (4) based on De Greef et al., (2010). Additionally, the social supports from family (8) is hypothesised to play a key role for achieved regular PA, Deshpande et al., (2005) mentioned that this supports more positive influence on female than male. Meanwhile, social supports could direct impact on PA (.04*) (Plotnikoff et al., 2006). It is hypothesised that improve social supports from family may help people with T2DM increase the PA level.

\section{Limitations and Conclusion}

Firstly, the usage of subjectively self-reported measurement is as an indicator of practising PA. It may cause over-reporting of PA by participants due to social desirability biases. Only De Greef et al., (2010) adopted both objective (accelerometer and pedometer) and selfreported assessment. Therefore, many of the subjective measurements are needed to assess precious PA in further studies. The second limitation is a lack of generalizability there are two potential reasons: 1) most studies adopted voluntary participants, selection bias may have occurred; 2) low response rate (33\%-51.7\%, see table 1). However, these studies presented in six different countries and ethnic groups that may improve the generalizability of this review.

Therefore, it is evident from the above that many factors of PA in middle aged and older people with T2DM exist. And Self-efficacy is an important determinant with PA. There is a need to clarify whether these variables are determinants and the causality between these variables. Nonetheless, theory-basement approach to studying PA in this population is required based upon this study.

\section{Acknowledgments}

This work was financially supported by Education Centre of Sichuan Province (Funding Number: 18ZB0189).

\section{References}

1. https://www.diabetes.org.uk/Documents/Position $\% 2$ 0statements/DiabetesUK_Facts_Stats_Oct16.pdf (2016).

2. Allen, N. A. Diabetes Educ30.5:805-819, (2004).

3. Association, American Diabetes. Diabetes Care (2017).

4. Bandura, Albert, Journal of Applied Psychology 12.1:169(1986).

5. Baranowski, Tom, C. Anderson, and C. Carmack . American Journal of Preventive Medicine 15.4:266297(1998).

6. Boulé, N. G., et al. Jama 12.1:1218-1227(2002).

7. Brennan, L. K. , et al. Health Education \& Behavior 30.30:740-755(2003).

8. Dalton, Alice M. , et al. Bmc Public Health 16.1:1171(2016).

9. Greef, Karlijn De, et al. Health Soc Care Community 19.2:0-0(2011).

10. Deshpande, A. D. , et al. Diabetes Care 28.5:10121018(2005)

11. Claude, Ferrand, P. Claire, and N. Sandra. Heart Lung \& Circulation 16.5:511-520(2010).

12. Grace, Sherry L. , et al. Journal of Behavioral Medicine 30.1:21-29(2007).

13. Heiss, Valerie J., and R. L. Petosa. Psychology, Health \& Medicine 21.1:1-10(2015).

14. None. Diabetes Research and Clinical Practice 107.2:308(2015). 
15. Lawton, J., Ahmad, N., Hanna, L. and Douglas, M. Health Education Research 21(1) : 43-54 (2005).

16. Orleans, T.C. Edited by Karen Glanz, Barbara K. Rimer, and K. Viswanath. 4th edn. San Francisco, CA: Jossey-Bass Inc.,U.S. (2008)

17. Plotnikoff, R. C. , S. Brez, and S. Brunet. Psychology, Health \& Medicine 8.4:7(2003).

18. Plotnikoff, Ronald C. , et al. Applied Psychology 57.4:628-643(2010).

19. Sallis, James F., et al. American Journal of Preventive Medicine 36.6:0-490(2009).

20. Sallis, James F., et al. Annu Rev Public Health 27.27:297-322(2006).

21. Sedgwick, P. 'Spearman' s rank correlation coefficient' , BMJ, 349 : g7327-g7327 (2014) .

22. Umpierre, Daniel, et al. Jama 305.17:1790(2011).

23. Stokols, D . Am Psychol 47.1:6-22(1992).

24. Stahl, T, et al. Social Science \& Medicine 52.1:110(2001).

25. Taylor, L.M., Leslie, E., Plotnikoff, R.C., Owen, N. and Spence, J.C., Annals of Behavioral Medicine, 35(2) : 170-178(2008).

26. Thomas, D. E., E. J. Elliott, and G. A. Naughton . Cochrane Database of Systematic Reviews 3.3:CD002968(2006).

27. Thomas, and N. Postgraduate Medical Journal 80.943:287-291(2004).

28. Trost, S. G., et al. Med.sci.sports Exerc34.12:1996(2002).

29. https://www.diabetes.org.uk/About_us/News_Landi ng_Page/UKs-poorest-twice-as-likely-to-havediabetes-and-its-complications/(2009). 